Çukurova Üniversitesi Mühendislik Mimarlık Fakültesi Dergisi, 33(3), ss. 207-216, Eylül 2018

Çukurova University Journal of the Faculty of Engineering and Architecture, 33(3), pp. 207-216, September 2018

\title{
ZnO-Grafen Nanokompozitinin Sol-Jel Yöntemiyle Üretimi ve Fotokatalizör Olarak Kullanılması
}

\author{
Ömer GÜLER ${ }^{* 1}$, Veyis SELEN ${ }^{2}$, Hasan SAFA ${ }^{1}$, Gülbeyi DURSUN ${ }^{3}$ \\ ${ }^{1}$ Mersin Üniversitesi, Mühendislik Fakültesi, Metalurji ve Malzeme Mühendisliği Bölümü, \\ Mersin \\ ${ }^{2}$ Fırat Üniversitesi, Mühendislik Fakültesi, Biyomühendislik Bölümü, Elazı̆̆ \\ ${ }^{3}$ Fırat Üniversitesi, Mühendislik Fakültesi, Kimya Mühendisliği Bölümü, Elazı̆̆
}

Geliş tarihi: 06.06.2018 Kabul tarihi: 15.10 .2018

$\ddot{\mathbf{O} z}$

$\mathrm{Bu}$ çalışmada Grafen-ZnO kompozitinin üretimi ve kısmi fotokatalitik özellikleri incelenmiştir. Kompozitte takviye elemanı olarak kullanılan grafen nano tabakalar sıvı faz eksfolasyon yöntemi ile üretilmiştir. Elde edilen bu tabakalar Sol-Jel prosesi sırasında ilave edilerek ZnO ile grafenin homojen karışması sağlanmıştır. Hatta bazı bölgelerde grafenler $\mathrm{ZnO}$ partikülleri tarafindan sarılmıştır. Sentezlenen grafenin karakterizasyonu geçirmeli elektron mikroskobu ve X-1şını analizleri ile yapılmıştır. Elde edilen kompozitin ise karakterizasyonu taramalı elektron mikroskobu ile yapılmıştır. Grafen-ZnO kompoziti kullanılarak RR195 boyarmaddenin fotokatalitik degradasyon yapılmıştır. Bunun sonucunda, ortamdaki Grafen-ZnO kompoziti konsantrasyonunun artışına paralel olarak renk giderim verimi 10,0 g/L Grafen-ZnO kompoziti konsantrasyonuna kadar artmıştır. Benzer eğilim TOC giderimi için de gözlemlenmiştir. Fotokatalitik reaksiyon süresi sonunda $(90 \mathrm{dk})$ 10,0 g/L Grafen-ZnO kompoziti kullanılan ortamda maksimum renk ve TOC giderim verimleri sirasıly \% 098,50 ve \%89,3 olarak ölçülmüştür.

Anahtar Kelimeler: Grafen, C.I. Reactive red 195, Fotokatalitik degradasyon, TOC, ZnO.

\section{Production of ZnO- Graphene Nanocomposite by Sol-Gel Method and used as a Photocatalyst}

\begin{abstract}
In this study, production and partial photocatalytic properties of the Graphene-ZnO composites were investigated. Graphene nano layers used as reinforcement element in the composite were produced via liquid phase exfoliation method. These nano layers were added during the sol-gel process to ensure homogeneous mixing of $\mathrm{ZnO}$ with the graphene. In some regions, graphene layers were observed to be surrounded by $\mathrm{ZnO}$ particles. Characterization of the synthesized graphene was carried out via transmission electron microscopy (TEM) and X-ray analysis. Photocatalytic degradation of the RR195 colorant was carried out by using $\mathrm{ZnO}$-graphene composites. As a result, with increasing concentration of
\end{abstract}

*Sorumlu yazar (Corresponding author): Ömer GÜLER, oguler@mersin.edu.tr 
Graphene- $\mathrm{ZnO}$ composite in the environment, the color removal efficiency increased to $10.0 \mathrm{~g} / \mathrm{L}$ Graphene- $\mathrm{ZnO}$ composition concentration. A similar propensity was observed for TOC removal. At the end of the photocatalytic reaction $(90 \mathrm{~min}$ ), in the environment using $10.0 \mathrm{~g} / \mathrm{L}$ Graphene- $\mathrm{ZnO}$ composition, maximum color and TOC removal efficiencies were measured as $98.50 \%$ and $89.3 \%$, respectively.

Keywords: C.I. Reactive red 195, Graphene, Photocatalytic degradation, TOC, ZnO

\section{GİRIŞ}

Tek katmanlı tek atomlu bir materyal olan grafen, geniş yüzey alanı ve olağanüstü elektriksel, termal, mekanik özellikleri ve düşük maliyetle büyük ölçekte üretilebilmesi nedeniyle yakın zamanda araştırmacıların dikkatini üstüne çekmeyi başarmıştır [1-3]. $\mathrm{Bu}$ sebepten dolayı çeşitli fonksiyonel kompozit malzemeler yapmak için önemli bir bileşen olarak yerini almıştır. Özellikle, grafen bazlı yarı iletken fotokatalizörler çevre ve enerji uygulamalarındaki kullanımları sayesinde bilim insanları tarafindan yoğun ilgi görmüştür [3]. Grafenin yüzey özellikleri, fonksiyonlaştırılmış grafen bazlı malzemelerin geliştirilmesi için çok iyi özellikler sunan kimyasal modifikasyon yöntemiyle iyileștirilebilir [3-5]. Bu tür grafen bazlı malzemeler, elektronik, optik ve iyi bir biyouyumluluk özelliği gösterdikleri için enerji depolama [6], kataliz [7], biyosensörler [8], moleküler görüntüleme [9] ve ilaç dağıtma [10] da dahil olmak üzere birçok potansiyel uygulamada kullanılabileceği tahmin edilmektedir [3].

Grafen birçok farklı üretim yöntemiyle elde edilebilmektedir. Bunların öne çıkanları mikromekaniksel olarak grafitin tabakalarının ayrılması (Eksfoliasyon) [11], kimyasal buhar biriktirme yöntemi [12], Grafen oksitin indirgenmesi [11] ve Epitaksiyel büyütme [13] olarak stralanabilir.

Grafen elde etmek için en iyi üretim yöntemler kimyasal indirgeme ya da 1 sıl işlem yoluyla grafitin yükseltgenmesi ve eksfoliasyon yöntemiyle grafen oksidin grafene dönüştürülmesidir $[2,14,15]$.

Son zamanlarda, fonksiyonelleștirilmiş grafen bazlı yarı iletken fotokatalizörler, iyi elektron iletkenliği, geniş spesifik alanı ve yüksek adsorpsiyonu nedeniyle çok dikkat çekmiştir $[3,15,16]$.

ZnO'nun düşük maliyetli, toksik olmayan, doğada bol miktarda bulunan, çevre dostu, mükemmel kimyasal ve mekanik kararlılık gibi avantajları vardır. $\mathrm{ZnO}$, yaklaşık $3,37 \mathrm{eV}$ genişliğinde doğrudan bant genişliği nedeniyle yaygın olarak kullanılan ve önemli bir yarı iletken fotokatalizör olarak kabul edilmektedir [17]. ZnO'nun piezoelektrik, doğal n-tipi iletkenlik, yüksek termal kararlılık, yüksek elektron hareketliliği gibi teknolojik özelliklerinden dolayı $\mathrm{ZnO}$ nanoyapı çalışmaları devamlılığını korumaktadır. Fotonik kristaller, katalizörler, 1şı $1 \mathrm{k}$ yayan diyotlar, sensörler, elektrominesans ve fotolüminesan gibi materyaller üzerinde geniş teknolojik uygulama alanına sahiptir $[15,17]$. UV veya görünür ışık ışınları altında organik kirleticilerin fotokatalitik bozunmasında da kullanılabilir [18].

$\mathrm{Ne}$ yazık ki, fotokatalitik alanda ZnO'nun endüstriyel uygulamasını engelleyen iki önemli dezavantaj vardır [19]. Bu nedenle kullanım olarak pek ideal değildir. İlk olarak, $\mathrm{ZnO}$ geniş bant boşluk enerjisine sahiptir. $\mathrm{ZnO}$ sadece ultraviyole (UV) 1şık ile uyarılabilen dar spektral yansıma aralığına sahiptir. İkincisi, ZnO'nun elektronboşluk çiftlerinin rekombinasyon oranını düşürmek ve $\mathrm{ZnO}$ 'nun ıșık emme aralığını değerli metal biriktirme yöntemleriyle arttırmak için $\mathrm{ZnO}$ tarafından üretilen foton oluşturulmuş elektron boşluk çiftleri kolaylıkla yeniden birleştirilebilir, böylece numunelerin fotokatalitik etkinliğini azaltır [20].

Karbon esasli malzemelerin $\mathrm{ZnO}$ ile hibritlenmesi sonucunda lineer olmayan ultra hizlı optik, optoelektronik, enerji depolama özellikleri ve fotokatalitik aktivite gibi saf $\mathrm{ZnO}$ 'ya kıyasla daha 
gelişmiş malzeme özellikleri elde edilmiştir $[15,17,21]$. Bu kompozitleri elde etmek ve yenilenmiş özelliklerini keşfetmek için termal ayrişma [22,23], kovalent olmayan modifikasyon [24] kovalent bağlanma [25], elektrokimyasal yol [26], ve sol-jel [27] prosesi gibi çeşitli yöntemler kullanılmıştır [28,29].

Bizim çalışmamızda da grafen nano tabaka üretilerek Sol-Gel ile üretilen $\mathrm{ZnO}$ içerisine takviye edilmiştir. Elde edilen kompozitin fotokatalitik katalizör olarak kullanımı C.I. Reactive Red 195 boyarmaddesinin sulu çözeltilerinde UV-C 1şık kaynağının kullanıldığ fotoreaktörde test edilmiştir.

\section{DENEYSEL ÇALIŞMA}

Grafen-ZnO kompoziti Sol-Gel metodu kullanılarak üretilmiştir. Takviye elemanı olarak kullanılan grafenler sıvı faz eksfolason yöntemi ile üretilmiştir. $\mathrm{Bu}$ üretim için, başlangıç malzemesi olarak \%99,5 saflıkta hegzagonal grafit (Merck) kullanılmıştır. Grafit önce $\mathrm{H}_{2} \mathrm{SO}_{4}-\mathrm{HCl}$ karışımından oluşan bir asit karışımı içerisinde 24 saat karıştırılmış ardından yıkanmış ve kurutulmuştur. Daha sonra bu toz $900{ }^{\circ} \mathrm{C}$ 'de 1 sıl işleme tabi tutulmuştur. $\mathrm{Bu}$ işlem sonunda expanded grafit elde edilmiştir. Elde edilen expanded grafit N-N dimetil formamid (Sigma Aldrich) içerisinde bir ultrasonik homojenizer (Bandelin HD 3200) yardımı ile 2 saat karıştırılmıştır. Bu işlem sonunda grafen nano tabakaların üretimi gerçekleştirilmiştir. Elde edilen grafen nano tabakalar TEM (JEOL Jem 2100F) incelemelerine tabi tutulmuştur.

Grafen-ZnO kompoziti sol-jel işlemi sırasında prosese eklenen grafen nano tabakalar ile üretilmiștir. Kompozitin üretimi için; 11 gr çinko asetatdihirat (2 molar) $25 \mathrm{ml}$ 2-metoxy etanol (etilen glikol monometil eter) içinde $60{ }^{\circ} \mathrm{C}$ 'de manyetik karıştırıcıda 20 dakika çözüldü. Ardından bu karışıma sentezlenmiş olan grafen nano tabakalar ilave edildi. Daha sonra karışım içerisine stabilizatör olarak $25 \mathrm{ml}$ etanolamin ilave edildi ve karışım manyetik karıştırıcıda 4 saat karıştırıldı. Elde edilen jel $600{ }^{\circ} \mathrm{C}$ 'de 8 saat havada kalsine edildi. Elde edilen bu ürün 10 dakika değirmende kırılarak toz haline getirildi.

Elde edilen kompozit XRD (Rigaku Smartlab) incelemesi ve SEM (Zeis Supra 55) incelemesi ile karakterize edildi.

C.I. Reactive Red 195 (RR195) (Çizelge 1, Şekil 1) Pisa Tekstil A.Ş.'den temin edilmiştir ve herhangi bir saflaştırma işlemi yapılmaksızın deneylerde kullanılmıştır. RR195 boyarmadde çözeltileri distile su ile hazırlanan stok çözeltiden $(1000 \mathrm{mg} / \mathrm{L})$ uygun seyreltmeler yapilarak deneylerde kullanılmıştır.

Çizelge 1. C.I. Reactive Red 195 (RR195) boyarmaddesinin bazı özellikleri

\begin{tabular}{|c|c|c|c|}
\hline Boyarmadde & Kimyasal Formül & Molekül Ağırlığı (g/mol) & $\lambda_{\text {max. }}$ \\
\hline C.I. Reactive Red 195 & $\mathrm{C}_{31} \mathrm{H}_{19} \mathrm{ClN}_{7} \mathrm{Na}_{5} \mathrm{O}_{19} \mathrm{~S}_{6}$ & 1136,3 & 540 \\
\hline
\end{tabular}<smiles>O=[N+]([O-])c1cc2cc(OS(=O)(=O)[O-])cc(Nc3nc(Cl)nc(Nc4cccc(S(=O)(=O)O[Na])c4)n3)c2c(O)c1N=Nc1ccc2c([N+](=O)[O-])cccc2c1S(=O)(=O)O[O-]</smiles>

Şekil 1. RR195 boyarmaddesinin kimyasal molekül yapısı [30] 
RR195 boyarmaddesinin Grafen-ZnO kompoziti katalizörlüğünde fotokatalitik degradasyonu şematik gösterimi Şekil 2'de verilen fotoreaktör düzeneğinde incelenmiştir. Fotoreaktör düzeneği merkezinde, kuvars camdan imal edilen ve UV-C ışık kaynağının korunmasını sağlayan bir kılıf bulunmaktadır. Fotoreaktörün dış kısmında ise sabit sıcaklıklarda çalışma imkanı sağlayan pyrex camdan yapılmış bir soğutma ceketi bulunmaktadır. UV 1 şı kaynağı olarak $21 \mathrm{~W}$ gücünde UV-C lamba kullanılmıştır. Fotoreaktörün çalışma hacmi 500 ml'dir. Fotoreaktör içerisine beslenen havanın dağıtılması amacıyla bir hava dağıtıcısı kullanılmıştır. Silindirik fotoreaktör düzeneği bir manyetik karıştırıcının üzerine yerleştirilerek fotoreaktör içerisindeki heterojen yapının karıştırılması sağlanmıştır.

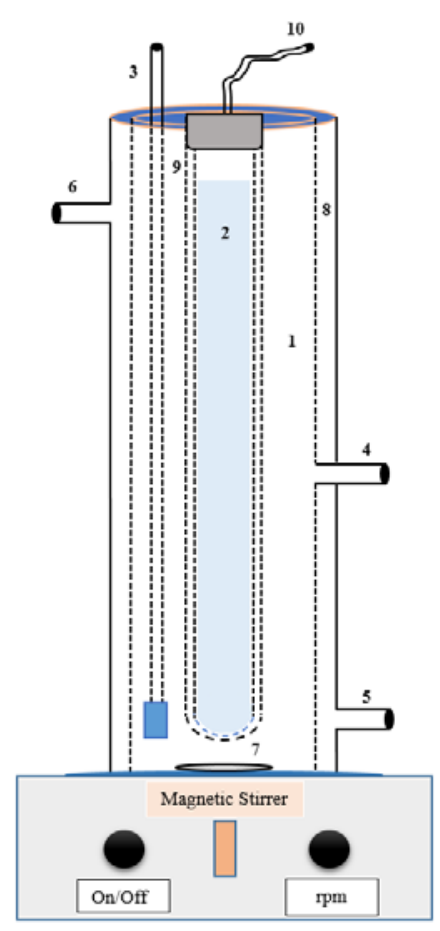

Şekil 2. Fotokatalitik reaktör sisteminin şematik gösterimi (1- Silindirik Fotokatalitik Reaktör; 2- UV-C Lamba; 3- Hava Beslemesi; 4- Numune Portu; 5- Soğutma Suyu Girişi; 6- Soğutma Suyu Çıkış1; 7- Manyetik Balık; 8- Soğutma Ceketi; 9- Lamba Kılıfi; 10- Güç Kaynağı)
RR195 boyarmaddesinin fotokatalitik renk ve TOC giderimi üzerine Grafen- $\mathrm{ZnO}$ kompoziti konsantrasyonu $\quad(0-10,0 \quad \mathrm{~g} / \mathrm{L})$ 'nun etkisi araştırılmıştır. Fotokatalitik renk ve TOC giderimi sırasında belirli zaman aralıklarında alınan numunelerde, Grafen-ZnO kompozit fotokatalizörü 14800 rpm'de $3 \mathrm{dk}$ süre ile santrifüjleme (Thermo CL21) sonunda ayrildiktan sonra supernatantta kalan RR195 boyarmaddesinin konsantrasyonu spektrofotometrik (Shimadzu UV/vis 1800) olarak $540 \mathrm{~nm}$ dalga boyunda yapılan okumalar sonucunda belirlenmiştir. Numunelerin TOC içeriği Shimadzu TOC-L cihazı kullanılarak belirlenmiştir. Herhangi bir andaki boyarmadde konsantrasyonu ve degradasyon verimi sirasiyla aşağıdaki eşitlikler kullanılarak hesaplanmıştır.

$\mathrm{C}_{\mathrm{t}}=\frac{\text { Absorbans }_{(\mathrm{OD} 540)}}{0,0129} \times$ Seyreltme Oran 1

Renk Giderim Verimi, \%=( $\left.\frac{\mathrm{C}_{0}-\mathrm{C}_{\mathrm{t}}}{\mathrm{C}_{0}}\right) \times 100$

TOC Giderimi $=\left(\frac{\mathrm{C}_{\mathrm{t}, \mathrm{TOC}}}{\mathrm{C}_{0, \mathrm{TOC}}}\right)$

$\mathrm{Bu}$ eşitliklerde; $\mathrm{C}_{0}$, başlangıç RR195 konsantrasyonunu $(\mathrm{mg} / \mathrm{L}) ; \mathrm{C}_{\mathrm{t}}$, herhangi bir $\mathrm{t}$ anındaki RR195 konsantrasyonunu (mg/L), $\mathrm{C}_{0, \mathrm{TOC}}$, başlangıç TOC konsantrasyonunu (mg/L); $\mathrm{C}_{\mathrm{t}, \mathrm{TOC}}$, herhangi bir $\mathrm{t}$ anındaki TOC konsantrasyonunu (mg/L) göstermektedir.

\section{SONUÇLAR}

Grafen üretmek için başlangıç malzemesi olarak kullanılan grafit, bir biri üzerine dizilmiş pek çok grafen tabakasından oluşmaktadır ve bu tabakalar bir birlerine zayıf Van der Waals bağları ile bağlıdırlar. $\mathrm{Bu}$ tabakalar arasındaki mesafe 0,334 nm'dir. $\mathrm{Bu}$ çalışmada takviye malzemesi olarak kullanılan grafen, sıvı faz eksfolasyon yöntemi ile üretilmiştir. $\mathrm{Bu}$ yöntem, grafit tabakalarının arasındaki zayıf bağları bazı solventler yardımıyla koparmaya ve tabakaların bir birinden ayrılmasına dayanan bir metottur. Direkt 
grafitin siv1 faz eksfolasyon yönteminde kullanılması durumunda elde edilen grafenlerin verimi azdır. Çünkü grafitteki grafen tabakaları arasındaki mesafe az olup solvent atomların bu tabakalar arasına girmesi güçleşmektedir. Bunun için, bu çalışmada grafit önce expanded grafite dönüştürülmüş arından da solvent olarak kullanılan N-N dimetil formamid (DMF) sayesinde grafen nano yabaların üretimi gerçekleştirilmiştir. Grafenin üretim şeması Şekil 3'de özetlenmiştir. Grafenin üretimi hakkındaki daha detaylı bilgi bizim daha önceki çalışmamızda bulunabilir [28].

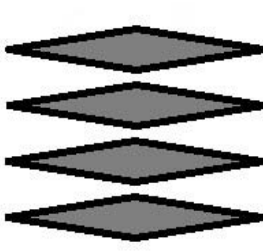

Graphite Layers

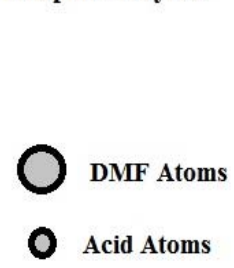

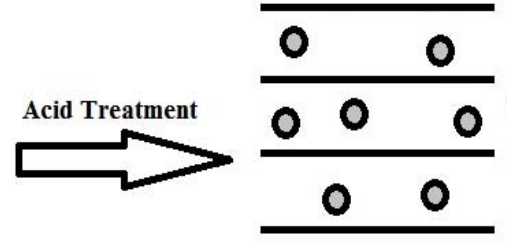

Expanded Graphite

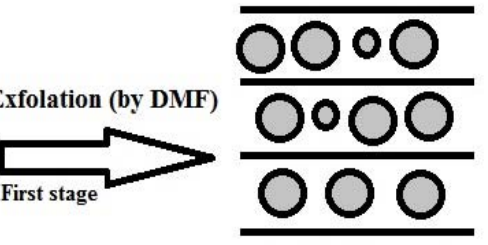

Entering DMF between sheets

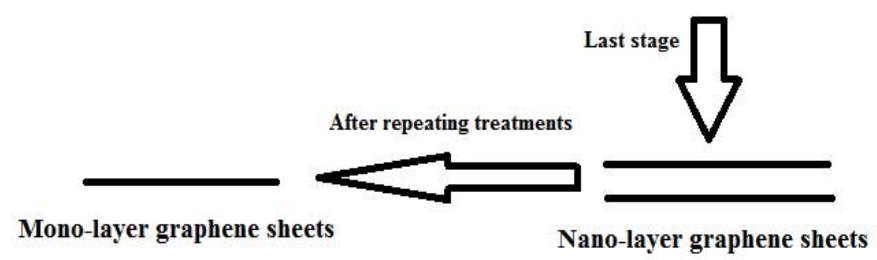

Şekil 3. Grafen nano tabakanın üretim şeması [28]

Şekil 4'de üretilen grafen nano tabakalara ait TEM görüntüsü verilmiştir. Şekilden de görüleceği gibi birkaç nano metre kalınlığında ve birkaç yüz nm genişliğinde tabakalar elde edilmiştir.

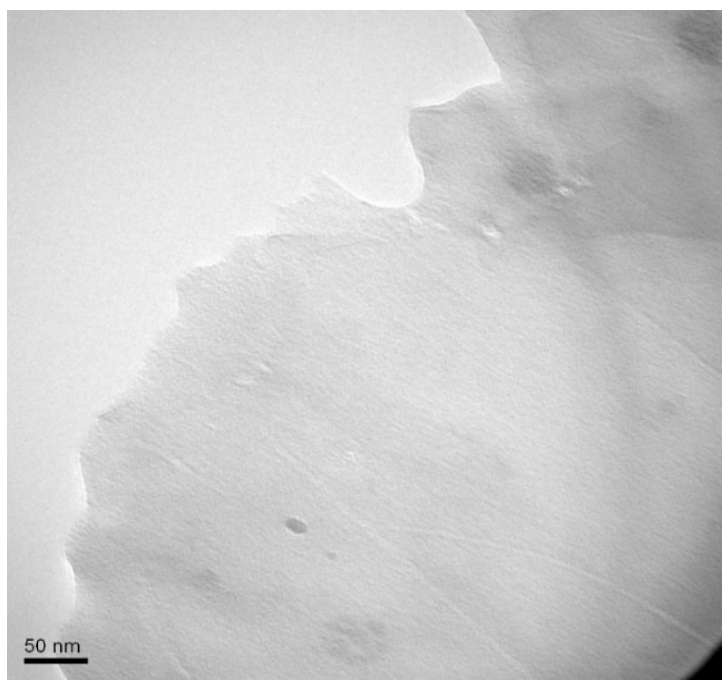

Şekil 4. Üretilen grafen nano tabakaların TEM görüntüsü
Şekil 5'de üretilmiş Grafen-ZnO kompozitinin XRD analizi verilmiştir. Şekilden de görüldüğü gibi (100), (002), (102), (110), (103), (200), (112), (201) pikleri karakteristik $\mathrm{ZnO}$ pikleridir. $\mathrm{Bu}$ piklere göre nispeten daha zayıf olan yaklaşık $28^{\circ}$ 'deki pik ise yapıda bulunan grafen ait pikdir. Grafenin miktarı nispeten düşük olduğu için pikin şiddeti de o oranda düşüktür. XRD analizi göstermektedir ki; ZnO-grafen kompoziti başarıyla üretilmiştir.

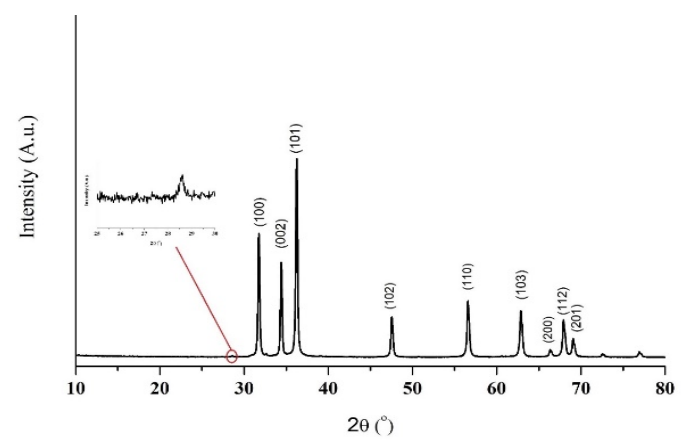

Şekil 5. Sol-Jel ile üretilen ZnO-Grafen kompozitinin XRD analizi 
Şekil 6a ve Şekil 6b'de üretilmiș olan kompozitin SEM görüntüsü verilmiştir. Sol-jel ile üretilen $\mathrm{ZnO}$ partiküllerinin boyutu $100 \mathrm{~nm}$ 'in altında olup partiküller küresel şekillidir. Bazı bölgelerde $\mathrm{ZnO}$ partikülleri topaklar halinde bulunmaktadır. ZnO'a grafen takviyesi sol-jel yönteminde jel

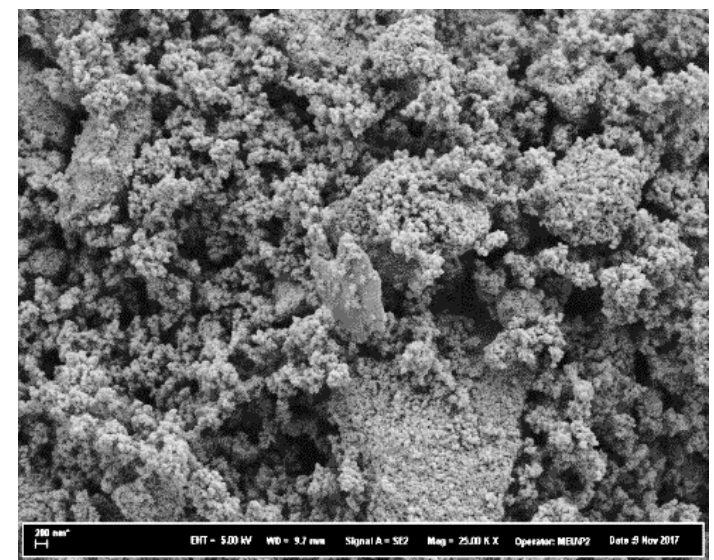

Şekil 6a. ZnO-Grafen

kompozitinin görüntüsü

\subsection{Grafen-ZnO Kompoziti Konsantrasyonunun Etkisi}

Grafen-ZnO kompoziti konsantrasyonunun RR195 boyarmaddesinin degradasyonuna etkisi, farklı Grafen-ZnO kompoziti konsantrasyonlarında $(0, \quad 2,5, \quad 5,0 \quad$ ve $\quad 10,0 \quad \mathrm{~g} / \mathrm{L}), \quad 100 \quad \mathrm{mg} / \mathrm{L}$ konsantrasyonundaki ve başlangıç $\mathrm{pH}$ 'ı $\left(\mathrm{pH}_{\mathrm{b}}\right) 5,2$ olan RR195 çözeltilerinin 90 dakika süre $(15 \mathrm{dk}$ karanlıkta ve $75 \mathrm{dk}$ UV-C altında), $1 \mathrm{~L} / \mathrm{dk}$ hava besleme hızında, $600 \mathrm{rpm}$ sabit karıştırma hızında ve $20{ }^{\circ} \mathrm{C}$ sabit sıcaklıkta ișletilen fotokatalitik reaktörde incelenmiștir. Elde edilen sonuçlar Şekil 7 ve Şekil 8'de verilmiştir.

Ortamdaki Grafen-ZnO kompoziti konsantrasyonunun artışına paralel olarak renk giderim verimi $10,0 \mathrm{~g} / \mathrm{L}$ Grafen-ZnO kompoziti konsantrasyonuna kadar artmıştır. Benzer eğilim Şekil 8'den de görüldüğü gibi TOC giderimi için de gözlemlenmiştir. Fotokatalitik reaksiyon süresi sonunda $(90 \mathrm{dk})$ 10,0 g/L Grafen-ZnO kompoziti kullanılan ortamda maksimum renk ve TOC giderim verimleri surasiyla $\% 98,50$ ve $\% 89,3$ olarak ölçülmüştür. $\mathrm{Bu}$ durum, Grafen-ZnO oluşumundan hemen önce katıldı̆̆ı için tüm grafen partikülleri $\mathrm{ZnO}$ partikülleri tarafından sarılmıștır. Başka bir ifadeyle, grafenler $\mathrm{ZnO}$ partiküllerinin içine gömülmüştür. Şekil 6b'de düz tabaka şeklindeki yapı grafendir. Bu tabakanın genişliği $500 \mathrm{~nm}$ 'den daha fazladır.

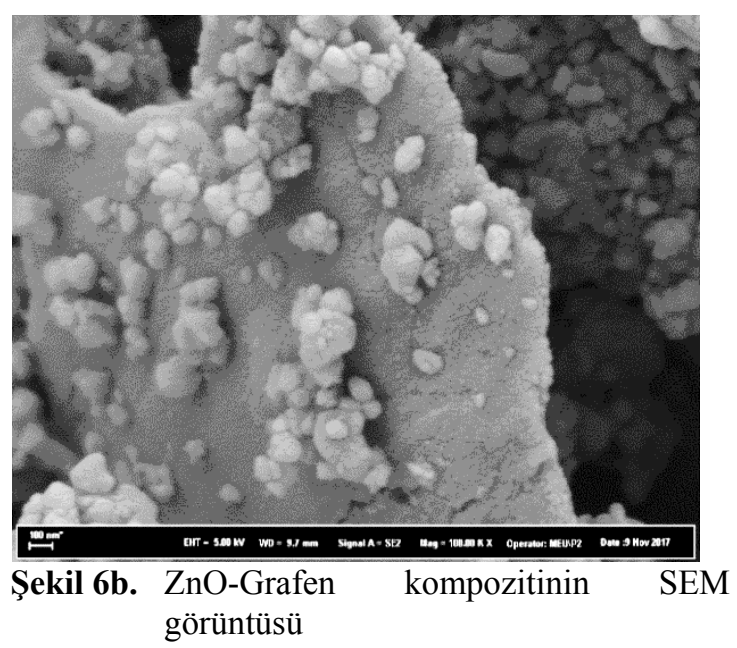

kompoziti ve RR195 boyarmadde çözeltisinden oluşan süspansiyona nüfuz eden UV ışının Grafen$\mathrm{ZnO}$ kompoziti yüzeyindeki aktif bölgelere absorplanan fotonlarının artışıyla birlikte üretilen $\mathrm{OH}^{\bullet} \quad$ radikallerinin miktarındaki artış ile açıklanabilir. Dolayısıyla ortamdaki Grafen-ZnO kompoziti konsantrasyonu arttıkça toplam aktif yüzey alanı ve degradasyon veriminin de artması beklenmektedir [31-33]. Fotoreaktörde gerçekleşen reaksiyon özet olarak aşağıdaki şekilde ifade edilebilir;

$$
\begin{aligned}
& \mathrm{G}-\mathrm{ZnO}+h v \longrightarrow(\mathrm{G}-\mathrm{ZnO})\left(\mathrm{e}_{\mathrm{CB}}^{-}+\mathrm{h}^{+}{ }_{\mathrm{VB}}\right) \\
& \mathrm{h}^{+}{ }_{\mathrm{VB}}+\mathrm{H}_{2} \mathrm{O} \longrightarrow \mathrm{H}^{+}+\mathrm{OH}^{\bullet} \\
& \mathrm{h}^{+}{ }_{\mathrm{VB}}+\mathrm{OH}^{-} \longrightarrow \mathrm{OH}^{\bullet} \\
& \mathrm{OH}^{\bullet}+\mathrm{RR} 195 \longrightarrow \mathrm{CO}_{2}+\mathrm{H}_{2} \mathrm{O}
\end{aligned}
$$

Burada; G-ZnO; fotokatalizör özelliği taşıyan Grafen-ZnO kompozitini, $h v$; UV 1şık tarafından sağlanan enerjiyi, $\mathrm{e}_{\mathrm{CB}}^{-}$; iletkenlik band 1 
elektronunu, $\mathrm{h}^{+}{ }_{\mathrm{VB}}$; değerlik bandını, $\mathrm{OH}^{\bullet}$ ise hidroksil radikalini temsil etmektedir.

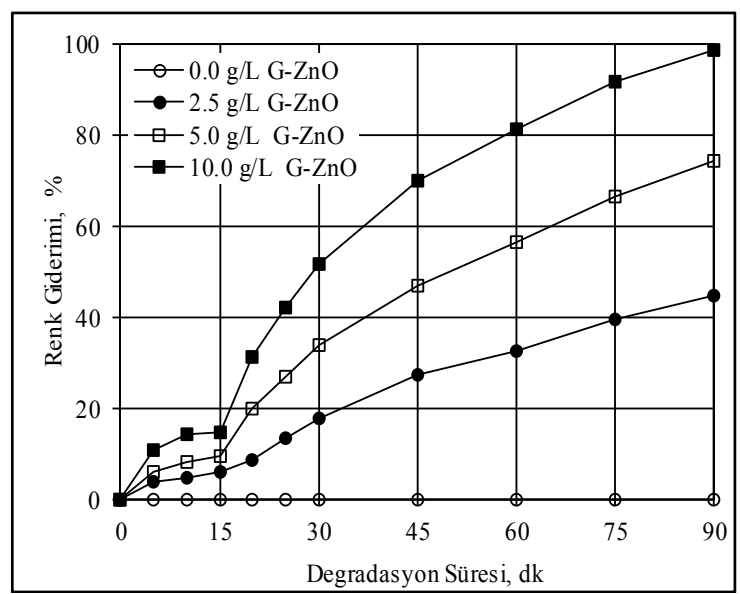

Şekil 7. Grafen-ZnO konsantrasyonunun RR195 boyarmaddesinin fotodegradasyon ile renk giderimi üzerine etkisi (Şartlar: 500 ml 100 mg/L RR195; Hava Besleme Hızı: 1,0 L/dk; Karıştırma Hızı: 600 rpm; $\mathrm{pH}_{\mathrm{b}}$ : 5,2; Degradasyon Sicaklığ $1: 20{ }^{\circ} \mathrm{C}$ )

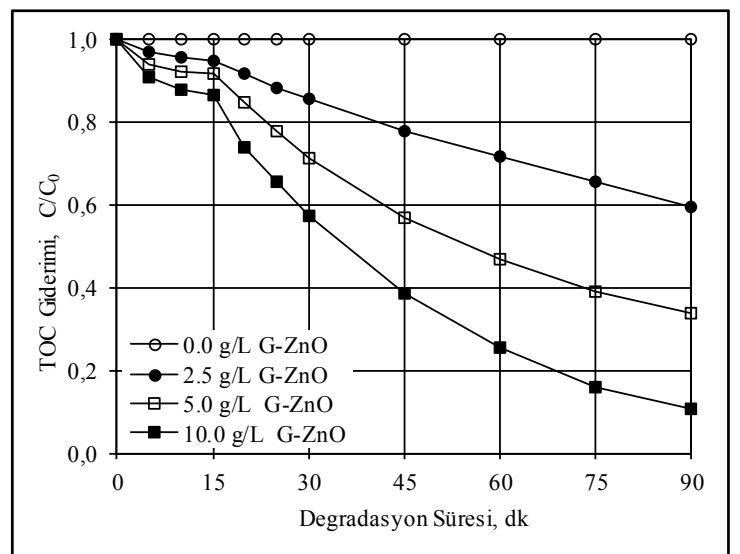

Şekil 8. Grafen-ZnO konsantrasyonunun RR195 boyarmaddesinin fotodegradasyon ile TOC giderimi üzerine etkisi (Şartlar: $500 \mathrm{ml} 100 \mathrm{mg} / \mathrm{L}$ RR195; Hava Besleme Hızı: 1.0 L/dk; Karıştırma Hızı: 600 rpm; $\mathrm{pH}_{\mathrm{b}}$ : 5.2; Degradasyon Sicaklığı: $20{ }^{\circ} \mathrm{C}$ )

Bu çalışma sonucunda, Grafen nano tabaka başarılı bir şekilde üretilerek Sol-Gel üretim tekniği ile üretilen $\mathrm{ZnO}$ içerisine takviye edilmiş ve Grafen$\mathrm{ZnO}$ nano kompoziti elde edilmiştir. Üretilen bu nano kompozitin fotokatalizör olarak kullanımı ile tekstil fabrikası atık sularında yaygın olarak bulunan C.I. Reactive Red 195 boyarmaddesinin tasarımı tarafımız tarafından gerçekleştirilen fotokatalitik reaktörde $\mathrm{TiO}_{2} / \mathrm{UV}-\mathrm{C}$ prosesi ile sulu çözeltilerinden renk giderim verimi üzerine Grafen-ZnO konsantrasyonunun renk ve TOC giderim verimi üzerine etkisi incelenmiştir. Sonuç olarak bu çalışmanın, tekstil endüstrisinde büyük bir sorun olan renkli atık suların arıtılmasında uygulanacak olan heterojen fotokatalitik degradasyon yöntemleri için kullanılan ticari fotokatalizörlere bir alternatif olacağ düşünülmektedir.

\section{KAYNAKLAR}

1. Guo, H.L., Wang, X.F., Qian, Q.Y., Wang, F.B., Xia, X.H. 2009. A Green Approach to the Synthesis of Graphene Nanosheets. Acs Nano, 3(9), 2653-2659.

2. Li, D., Muller, M.B., Gilje, S., Kaner, R.B., Wallace, G.G. 2008. Processable Aqueous Dispersions of Graphene Nanosheets. Nature Nanotechnology, 3(2), 101-105.

3. Xiang, Q.J., J.G. Yu, M. Jaroniec, 2012. Graphene-based Semiconductor Photocatalysts. Chemical Society Reviews, 41(2), 782-796.

4. Sun, Y.Q., Wu, Q.O., Shi, G.Q. 2011. Graphene Based New Energy Materials. Energy \& Environmental Science, 4(4), 11131132.

5. Stankovich, S., Dikin, D.A., Dommett, G.H.B. Kohlhaas, K.M., Zimney, E.J., Stach, E.A., Piner, R.D., Nguyen, S.T., Ruoff, R.S. 2006. Graphene-based Composite Materials. Nature, 442(7100), 282-286.

6. Wang, K., Ruan, J., Song, H., Zhang, J.L., Wo, Y., Guo, S.W., Cui, D.X. 2011. Biocompatibility of Graphene Oxide. Nanoscale Research Letters, 6(8), 1-8.

7. Wang, Q., Guo, X.F., Cai, L.C., Cao, Y., Gan, L., Liu, S., Wang, Z.X., Zhang, H.T., Li, L.D. 2011. $\mathrm{TiO}^{2}$-decorated Graphenes as Efficient Photoswitches with High Oxygen Sensitivity. Chemical Science, 2(9), 1860-1864. 
8. Park, S., Mohanty, N., Suk, J.W., Nagaraja, A., An, J.H., Piner, R.D., Cai, W.W., Dreyer, D.R., Berry, V., Ruoff, R.S. 2010. Biocompatible, Robust Free-Standing Paper Composed of a TWEEN/Graphene Composite. Advanced Materials, 22(15), 1736-1740.

9. Cai, W.B., Chen, X.Y. 2007. Nanoplatforms for Targeted Molecular Imaging in Living Subjects. Small, 3(11), 1840-1854.

10. Akhavan, O., Ghaderi, E., Esfandiar, A. 2011. Wrapping Bacteria by Graphene Nanosheets for Isolation from Environment, Reactivation by Sonication, and Inactivation by NearInfrared Irradiation. Journal of Physical Chemistry B, 115(19), 6279-6288.

11. Park, S., Ruoff, R.S. 2009. Chemical Methods for the Production of Graphenes. Nature Nanotechnology, 4(4), 217-224.

12. Reina, A., Jia, X.T., Ho, J., Nezich, D., Son, H.B., Bulovic, V., Dresselhaus, M.S., Kong, J. 2009. Large Area, Few-Layer Graphene Films on Arbitrary Substrates by Chemical Vapor Deposition. Nano Letters, 9(1), 30-35.

13. Kosynkin, D.V., Higginbotham, A.L., Sinitskii, A., Lomeda, J.R., Dimiev, A., Price, B.K., Tour, J.M. 2009. Longitudinal Unzipping of Carbon Nanotubes to form Graphene Nanoribbons. Nature, 458(7240), 872-875.

14. Schniepp, H.C., Li, J.L., McAllister, M.J., Sai, H., Herrera-Alonso, M., Adamson, D.H., Prud'homme, R.K., Car, R., Saville, D.A., Aksay, I.A. 2006. Functionalized Single Graphene Sheets Derived from Splitting Graphite Oxide. Journal of Physical Chemistry B, 110(17), 8535-8539.

15. Yang, Y., Ren, L.L., Zhang, C., Huang, S., Liu, T.X. 2011. Facile Fabrication of Functionalized Graphene Sheets (FGS)/ZnO Nanocomposites with Photocatalytic Property. Acs Applied Materials \& Interfaces, 3(7), 2779-2785.

16. Wang, S., Goh, B.M., Manga, K.K., Bao, Q.L., Yang, P., Loh, K.P. 2010. Graphene as Atomic Template and Structural Scaffold in the Synthesis of Graphene-Organic Hybrid Wire with Photovoltaic Properties. Acs Nano, 4(10), 6180-6186.

17. Pearton, S.J., Norton, D.P., Ip, K., Heo, Y.W., Steiner, T. 2005. Recent Progress in Processing and Properties of $\mathrm{ZnO}$. Progress in Materials Science, 50(3), 293-340.

18. Lee, K.R., Park, S., Lee, K.W. 2003. Rapid Ag Recovery Using Photocatalytic $\mathrm{ZnO}$ Nanopowders Prepared by Solutioncombustion Method. Journal of Materials Science Letters, 22(1), 65-67.

19. Chouhan, N., Ameta, R., Meena, R.K., Mandawat, N., Ghildiyal, R. 2016. Visible Light Harvesting $\mathrm{Pt} / \mathrm{CdS} / \mathrm{Co}$-doped $\mathrm{ZnO}$ Nanorods Molecular Device for Hydrogen Generation. International Journal of Hydrogen Energy, 41(4), 2298-2306.

20. Wang, L., Ji, Z.Y., Lin, J.J., Li, P. 2017. Preparation and Optical and Photocatalytic Properties of Ce-doped $\mathrm{ZnO}$ Microstructures by Simple Solution Method. Materials Science in Semiconductor Processing, 71, 401-408.

21. Janotti, A., Van de Walle, C.G. 2009. Fundamentals of Zinc Oxide as a Semiconductor. Reports on Progress in Physics, 72(12), 1-29.

22. Dou, S.M., Liu, Q.H., Wang, W.L., Liu, X.M. 2010. Highly Ordered Lattice Orientation of ZnO Nanoparticles Formed in Confined Space. Chinese Journal of Chemical Physics, 23(4), 484-490.

23. Guo, G., Guo, J., Tao, D., Choy, W.C.H., Zhao, L., Qian, W., Wang, Z. 2007. A Simple Method to Prepare Multi-walled Carbon Nanotube/ZnO Nanoparticle Composites. Applied Physics a-Materials Science \& Processing, 89(2), 525-528.

24. Jiang, L.Q., Gao, L. 2005. Fabrication and Characterization of $\mathrm{ZnO}$-coated Multi-walled Carbon Nanotubes with Enhanced Photocatalytic Activity. Materials Chemistry and Physics, 91(2-3), 313-316.

25. Zhang, N., Sun, J., Jiang, D.Y., Feng, T., Li, Q. 2009. Anchoring Zinc Oxide Quantum Dots on Functionalized Multi-walled Carbon Nanotubes by Covalent Coupling. Carbon, 47(5), 1214-1219.

26. Zhang, R.X., Fan, L.Z., Fang, Y.P., Yang, S.H. 2008. Electrochemical Route to the Preparation of Highly Dispersed Composites of $\mathrm{ZnO} /$ carbon Nanotubes with Significantly Enhanced Electrochemiluminescence from 
ZnO. Journal of Materials Chemistry, 18(41), 4964-4970.

27.Zhu, L.P., Liao, G.H., Huang, W.Y., Ma, L.L., Yang, Y., Yu, Y., Fu, S.Y. 2009. Preparation, Characterization and Photocatalytic Properties of ZnO-coated Multi-walled Carbon Nanotubes. Materials Science and Engineering B-Advanced Functional Solid-State Materials, 163(3), 194-198.

28. Guler, O., Guler, S.H., Selen, V., Albayrak, M.G., Evin, E. 2016. Production of Graphene Layer by Liquid-phase Exfoliation with Low Sonication Power and Sonication Time from Synthesized Expanded Graphite. Fullerenes Nanotubes and Carbon Nanostructures, 24(2), 123-127.

29. Kavitha, T., Gopalan, A.I., Lee, K.P., Park, S.Y. 2012. Glucose Sensing, Photocatalytic and Antibacterial Properties of Graphene-ZnO Nanoparticle Hybrids. Carbon, 50(8), 2994-3000.

30. Dursun, A.Y., Tepe, O. 2011. Removal of Chemazol Reactive Red 195 from Aqueous Solution by Dehydrated Beet Pulp Carbon. Journal of Hazardous Materials, 194, 303-311.

31. Kalantary, R.R., Shahamat, Y.D., Farzadkia, M., Esrafili, A., Asgharnia, H. 2015. Photocatalytic Degradation and Mineralization of Diazinon in Aqueous Solution Using Nano$\mathrm{TiO}^{2}$ (Degussa, P25): Kinetic and Statistical Analysis. Desalination and Water Treatment, 55(2), 555-563.

32. Karaoglu, M.H., Ugurlu, M. 2010. Studies on $\mathrm{UV} / \mathrm{NaOCl} / \mathrm{TiO}^{2} / \mathrm{Sep} \quad$ Photocatalysed Degradation of Reactive Red 195. Journal of Hazardous Materials, 174(1-3), 864-871.

33. Rauf, M.A., Meetani, M.A., Hisaindee, S. 2011. An Overview on the Photocatalytic Degradation of Azo Dyes in the Presence of $\mathrm{TiO}_{2}$ Doped with Selective Transition Metals. Desalination, 276(1-3), 13-27. 
